\title{
Basic Blue 41 ve Basic Red 46 Boyar Maddelerinin Çözeltiden Anyonik Polimer Membran ile Giderilmesi
}

\author{
${ }^{* 1}$ Reyhan Ozdogan, ${ }^{1}$ Mithat Celebi \\ ${ }^{1}$ Mühendislik Fakültesi, Polimer Mühendisliği Bölümü, Yalova Üniversitesi, Türkiye \\ mithat.celebi@yalova.edu.tr \\ Geliş Tarihi: 2017-02-06 Kabul Tarihi: 2018-01-31
}

\begin{abstract}
Öz
Endüstriyel atık sular içerisinde tekstil atık suları çok çeşitli kimyasallar ve boyar maddeler içermelerinden dolayı dikkat çekmektedirler. Bu boyar maddeleri su kaynaklarına, ırmaklara ve denizlere arıtılmadan bırakıldıklarında suda yaşayan canlılar ve besin zinciri olumsuz etkilenmektedir. Bu zararlı etkilerin en aza indirilmesi için endüstriyel atık suların arıtılması canlılar için hayati önem taşımaktadır. Bu çalışmada, akrilik elyafların boyanmasında kullanılan iki farklı bazik karakterdeki tekstil boyar maddesi (Basic Blue 41-BB41 and Basic Red 46-BR46) farklı $\mathrm{pH}$, süre, sıcaklık ve başlangıç boyar madde konsantrasyonlarında sülfonik asit esaslı polimerik membran ile çözelti ortamından \% 75 ile \% 100 aralığında boyar madde giderme yüzdesi ile giderildi. Gibbs serbest enerjisi $(\Delta \mathrm{G})$ değerleri BB41 ve BR46 boyar maddeleri için $318 \mathrm{~K}$ 'de sırası ile $-5.2 \mathrm{kj} / \mathrm{mol}$ ve $-5,52 \mathrm{kj} / \mathrm{mol}$ olarak bulundu. Adsorpsiyon izotermleri incelendiğinde her iki boyar maddenin polimer membranına adsorpsiyonunun Freundlich izotermine uyduğu tespit edildi.
\end{abstract}

Anahtar kelimeler: adsorpsiyon, akrilik elyaf, atık su, bazik boyar madde, Nafion ${ }^{\circledR}$ membran

\section{Elimination of Basic Blue 41 ve Basic Red 46 Dyestuffs from Solution by Anionic Polymer Membrane}

\author{
${ }^{* 1}$ Reyhan Ozdogan, ${ }^{1}$ Mithat Celebi \\ 1Faculty of Engineering, Department of Polymer Engineering, Yalova University, Turkey \\ mithat.celebi@yalova.edu.tr
}

\begin{abstract}
Textile wastewaters in industrial wastewaters are attracting attention because of containing a various chemicals and dyestuffs. When these dyestuffs are discharge to water resources, rivers and seas, the aquatic life and food chain without any treatment are adversely affected. The treatment of industrial wastewater is vital for all living creatures to minimize these harmful effects. Two different basic dyestuffs (Basic Blue 41-BB41 and Basic Red 46-BR46), which are used to dyeing of acrylic fibers were removed from the solution with a sulfonic acid based polymeric membrane adsorbent at different $\mathrm{pH}$, time, temperature and initial dyestuff concentration with $75 \%$ to $100 \%$ removal percentage range values in this study. The Gibbs free energy $(\Delta \mathrm{G})$ values were found to be -5.2 $\mathrm{kJ} / \mathrm{mol}$ and $-5.52 \mathrm{~kJ} / \mathrm{mol}$ for the BB41 and BR 46 dyes, respectively, at $318 \mathrm{~K}$. According to the adsorption isotherms, the adsorption of both dyestuffs on the polymer membrane were fit to the Freundlich isotherm.
\end{abstract}

Keywords: acrylic fiber, adsorption, basic dyestuff, Nafion ${ }^{\circledR}$ membrane, wastewater 
R. OZDOGAN/APJES 6-1 (2018) 17-24

\section{GíRIşs}

Sentetik boyar maddeler yılda 0,7-0,8 milyon tondan fazla dünya çapında üretilerek endüstride değişik sektörlerde kullanılmaktadır. Yaklaşık 10.000 farklı boya ve pigment endüstriyel olarak kullanılmaktadır. Tekstil, kağıt, gıda, plastik ve kozmetik gibi çeşitli sektörlerden renkli atık su deşarjı ile ilgili sorunlar hükümetlerin ve bilim insanlarının dikkatini çekmektedir [1]. Tekstil endüstrisinde boyama işlemleri sırasında genellikle renkli, yüksek kimyasal ve biyolojik oksijen ihtiyacı, kullanılan işleme ve boyar madde türüne göre farklı $\mathrm{pH}^{\prime}$ larda atık sular meydana gelmektedir. Atık suların ekosistem için doğrudan risk oluşturmaları nedeniyle arıtmaları önemlidir [2]. Boyar maddelerin bir kısmı kanserojen olduklarından ve suda oluşturdukları renk nedeniyle güneş 1şı̆ğını engellemeleri, fotosentezi azaltması ve görüntü kirliliği oluşturduklarından dolayı atık sulardan bertaraf edilmeleri gerekmektedir [3].
Organik moleküller olarak bilinen boyar maddelerin çoğu suda çözünürken (katyonik-bazik, asid, metal kompleks, direk ve reaktif boyar maddeler), sadece dispers boyalar suda dispersiyon halinde bulunurlar. Boyar maddeler yaygın olarak iki farklı şekilde kimyasal yapılarına ve kullanım amacına göre siniflandirılırlar. Endüstride boyar maddeler daha çok kullanım amacına göre sınıflandırıldıkları isimleri ile bilinmektedir [4],[5]. Yaygın olarak kullanılan boyar maddelerin kimyasal yapısı ve oluşturdukları kirlilik Çizelge 1'de özetlenmektedir [6]. Moleküllerinde pozitif yük taşıyan boyar maddelere katyonik boyar maddeler veya bazik boyar maddeler adı verilir [7]. Bazik boyar maddeler genellikle asetik asit veya tannik asit yardımıla 80-90 ${ }^{\circ} \mathrm{C}$ 'de akrilik elyafını hızlı bir şekilde boyarlar ve kumaşa güçlü bir şekilde bağlanırlar. Bazik boyar maddeler tekstil endüstrisinde özellikle akrilik elyafların boyanmasında kullanılmaktadır. [3], [8].

Tablo 1. Boyar maddelerin sınıfları, kimyasal grupları ve oluşan kirlilik

Atık

\begin{tabular}{|c|c|c|c|}
\hline 10 & Özellikleri & Kimyasal Grupları & Oluşan Kirlilik \\
\hline Asit & Suda çözünür & $\begin{array}{l}\text { Azo, nitro, nitrozo, } \\
\text { trifenilmetan, ksanten }\end{array}$ & $\begin{array}{l}\text { Renk, organik asitler, } \\
\text { bağlanmayan boyar madde }\end{array}$ \\
\hline Bazik & $\begin{array}{l}\text { Suda çözünür, yüksek } \\
\text { parlaklik }\end{array}$ & $\begin{array}{l}\text { azo, triarilmetan, ksanten, } \\
\text { akridin, oksazin, antrakinon }\end{array}$ & $\begin{array}{l}\text { Renk, bağlanmayan boyar } \\
\text { madde }\end{array}$ \\
\hline Direkt & $\begin{array}{l}\text { Suda çözünür, elyafa } \\
\text { doğrudan uygulanır }\end{array}$ & $\begin{array}{l}\text { Azo, fitalosiyanin, stilben, } \\
\text { oksazin }\end{array}$ & $\begin{array}{l}\text { Renk, tuz, bağlanmayan } \\
\text { boyar madde, yüzey aktif } \\
\text { maddeler }\end{array}$ \\
\hline Dispers & Suda çözünmez & Azo, antrakinon, nitro & $\begin{array}{l}\text { Renk, organik asitler, } \\
\text { fosfatlar, köpük kırıcılar, } \\
\text { ağartıcılar, dispersantlar }\end{array}$ \\
\hline Reaktif & $\begin{array}{l}\text { Suda çözünür, en geniş } \\
\text { boyar madde sinıfi }\end{array}$ & $\begin{array}{l}\text { Azo, antrakinon, fitalosiyanin, } \\
\text { formazon, oksazin }\end{array}$ & $\begin{array}{l}\text { Renk, tuz, alkalinite, } \\
\text { bağlanmayan boyar madde, } \\
\text { yüzey aktif maddeler, köpük } \\
\text { kırıcılar }\end{array}$ \\
\hline
\end{tabular}

sulardan boyar maddelerin giderilmesinde ana başlıklar halinde fiziksel, kimyasal ve biyolojik yöntemler kullanılmaktadır. Bu yöntemler içerisinde polielektrolitler ile flokulasyon ve koagülasyon, oksidasyon, ozonlama, membran ile ayırma, değişik fonksiyonel gruplar içeren tasarlanmış polimerlere zehirli ve renkli kimyasalların adsorpsiyonu ve anaerobik arıtma gibi yöntemler ayrı olarak veya birden fazla yöntemin birbirinin ardı sira kullanılması atık suyun karakterizasyonuna göre tercih edilmektedir [2], [9]-[12]. Tekstil endüstrisi kaynaklı renkli atık suların gideriminde polimerler polielektrolit veya adsorban olarak kullanılmaktadır. Adsorban materyalinin tekrar kullanılabilmesi ekonomik olması açısından önemlidir. Aktif karbon, kitosan, zeolitler, killer, bazı endüstriyel atıklar ve tarımsal atıklar boyar maddelerin giderilmesinde sıklıkla kullanılan adsorbanlar arasında yer almaktadır [11], [13]-[16]. Literatürde perfluorosülfonik asit esaslı polimerik membran (Nafion ${ }^{\circledR)}$ ile bazik boyar maddelerin giderilmesine ait herhangi bir çalışmaya rastlanmamıştır. Bu çalışmada, perfluorosülfonik asit esaslı polimerik membran adsorban materyali olarak kullanılarak iki farklı bazik boyar maddenin (Basic Blue 41 ve Basic Red 46) farklı koşullarda (pH, sıcaklık, başlangıç boyar madde konsantrasyonu) giderilmesi incelendi. 


\section{MALZEME VE YÖNTEM}

Çalışmada kullanılan bazik boyar maddeleri akrilik elyaf fabrikasından temin edildi. Kullanılan boyar maddelerin özellikleri Çizelge 2'de gösterildi. Adsorban materyali olarak Nafion ${ }^{\circledR} \mathrm{N}-117$ ticari islimli membran Alfa Aesar firmasından satın alındı. $\mathrm{Bu}$ membran genel olarak yakıt pillerinde kullanılmaktadır. Membranın kalınlığı: $0,180 \mathrm{~mm}$ ve iyon değiştirme kapasitesi ise $\geq 0,9 \mathrm{meq} / \mathrm{g}$ 'dir. Ultra saf su Millipore MilliQ sisteminden elde edildi. Asetik asit (Fluka), sodyum fosfat dibazik (Riedelde Haen), monobazik fosfat (Riedel-de Haen), disodyum sitrat tamponu $(0,05 \mathrm{M}, \mathrm{pH}: 3,0)$, fosfat tamponu (0,1 M, pH: 7,0$)$, sodyum asetat tamponu $(0,05 \mathrm{M}, \mathrm{pH}: 5,0)$ boyar madde giderme çalışmalarında kullanıldı.

Tablo 2. Çalışmada kullanılan bazik boyar maddelerin özellikleri

\begin{tabular}{lll}
\hline Boyar madde & $\begin{array}{l}\text { Molekül ağırlığ } \\
(\mathrm{g} / \mathrm{mol})\end{array}$ & $\begin{array}{l}\text { Maksimum absorbans } \\
\text { dalgaboyu }\left(\lambda_{\max }\right)\end{array}$ \\
\hline Basic Blue 41 (BB41) & 482,57 & 609 \\
Basic Red 46 (BR 46) & 403,32 & 530 \\
\hline
\end{tabular}<smiles>CCN(CCO)c1ccc(N=Nc2sc3ccccc3[n+]2C)cc1</smiles>

Şekil 1. Basic Blue 41 Boyar maddesi<smiles>CN(Cc1ccccc1)c1ccc(N=Nc2n(C)cn[n+]2C)cc1</smiles>

Şekil 2. Basic Red 46 Boyar maddesi

\subsection{Boyar Madde Çözeltilerinin Hazırlanması ve Giderilmesi}

Boyar madde çözeltileri (Basic Blue 41 ve Basic Red 46) $1000 \mathrm{mg} / \mathrm{L}$ konsantrasyonda destile su ile hazırland1. İstenen konsantrasyonlar bu boyar madde çözeltisi seyreltilerek hazırlandı. Hazırlanan boyar madde çözeltilerinin maksimum dalga boyları UVVis.'de 200-800 nm arasında spektrum alınarak belirlendi. Maksimum dalga boyunda okunan absorbans değerleri 1,0'in üzerinde olduğunda daha hassas absorbans değeri okunması için boyar madde çözeltileri destile su seyreltildi. Maksimum absorbans değerinde okunan absorbans değerleri seyreltme faktörü ile çarpılarak boyar madde çözeltilerinin başlangıç absorbsiyon değerleri hesapland. Hazırlanan çözeltilerin pH'ları 1N $\mathrm{NaOH}$ veya $1 \mathrm{~N} \mathrm{HCl} \mathrm{kullanılarak} \mathrm{ayarland1.} 60 \mathrm{mg}$ anyonik polimer sentetik boyar madde çözeltilerine ilave edilip 250 rpm'de bir saat karıştırıldı. Boyar maddelerin başlangıç boyar madde konsantrasyonu $60 \mathrm{mg} / \mathrm{L}$ 'dır. Boyar maddelerin giderimi boyaların maksimum dalga boyundaki azalmanın UV-Vis. Spekrofotometre (Shimadzu, UV-1800) incelenmesi ile belirlendi. Boyar maddelerin yüzde giderimi değerleri Eşitlik 1'e göre hesapland1.

$$
\text { Boyar madde giderme (\%): } \frac{(A b s(i)-A b s(t))}{A b s(i)} \times 100 \quad \text { Eşitlik } 1 .
$$


Abs (i): boyar maddenin maksimum dalga boyunda gösterdiği absorbans değeri

Abs (t): Boyar maddeye adsorban ilavesinden sonra geçen sürenin sonunda maksimum dalga boyundaki absorbans değeri.

\subsection{Adsorpsiyon Kinetiklerinin Hesaplanması ve Termodinamik Çalışmaları}

\section{Lugmuir İzotermi}

$$
q_{e}=\frac{\left(c_{o}-c_{e}\right) \cdot V}{m}
$$

Eşitlik 2.

$\mathrm{q}_{\mathrm{e}}$ : adsorpsiyon kapasitesi (mg/g); $\mathrm{C}_{\mathrm{o}}$ : boyar maddenin başlangıç konsantrasyonu (mg/L); $\mathrm{C}_{\mathrm{e}}$ : çözeltideki boyar maddenin konsantrasyonu (mg/L); V: Çözelti hacmi (L); m: adsorban ağırlığı (g); qm: adsorbanın maksimum adsorplama kapasitesi; $\mathrm{K}_{\mathrm{L}}$ : Langmuir adsorpsiyon sabiti.

Eşitlik 2. kullanılarak adsorbanın adsorpsiyon kapasitesi mg/g olarak hesapland.

$$
\frac{C_{e}}{q_{e}}=\frac{1}{q_{m} \cdot K_{L}}+\frac{1}{q_{m}} C_{e}
$$

Eşitlik 3.

Eşitlik 3'e göre $C_{e}$ 'ye karşı $\frac{C_{e}}{q_{e}}$ grafiğe geçirilirse doğrunun eğiminden $q_{m}$, kayma değerinden ise $K_{L}$ sabiti hesapland.

\section{Freundlich İzotermi}

$$
\ln q_{e}=\ln K_{f}+\frac{1}{n} \ln C_{e}
$$

\section{Eşitlik 4.}

$K_{f}$ : Freundlich sabiti; n: sabittir (n > 1 ). Eşitlik 4'e göre $\ln q_{e}$ 'ye karşı $\ln C_{e}$ grafiğe geçirildi ve doğrunun eğiminden $\mathrm{n}$, kayma değerinden ise $K_{f}$ sabiti hesapland1.

\section{BULGULAR}

Bazik boyar maddelerin giderilmesinde literatürde son yillarda kullanılan adsorbanlar arasında; bor ve atıkları [25], kitosan [13], [19], bazı endüstriyel atıklar [17] ve tarımsal atıklar [15], [16], [20] yer almaktadır. Gupta ve ark. (2016), bor ile zenginleştirilmiş atıkları ve melası Basic Blue 41 ve Basic Red 46 boyar maddelerinin giderilmesinde kullanmışlardır [17].

Bu çalışmada, Basic Blue 41 (BB41) ve Basic Red 46 (BR46) bazik boyar maddeleri farklı süre, sıcaklık, pH ve başlangıç boyar madde konsantrasyonlarında perfluorosülfonik asit esaslı polimer ile giderildi. Şekil 3 'te boyar madde giderme yüzdesi sıcaklığın artması ile arttığı görülmektedir. 45 oC ile 65 oC arasında boyar madde giderme yüzdesi birbirinden çok farklı olmadığı için bundan sonraki deneyler daha fazla enerji kullanmamak için 45 oC'de yapıldı.

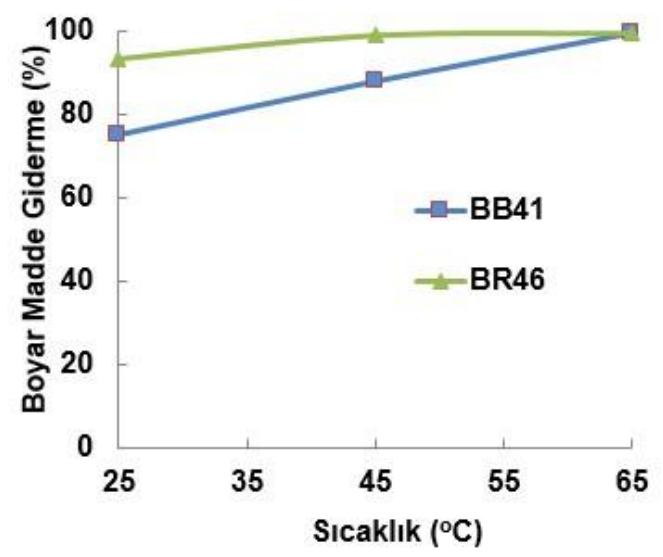

Şekil 3. Bazik boyar maddelerin pH:7,0 ve 60 dakika boyunca farklı sıcaklıklarda elde edilen yüzde boyar madde giderme değerleri

S1caklık arttıkça boyar maddenin adsorbana tutunması da artarak boyar madde giderme yüzdesi arttı (Şekil 3). Her iki boyar madde 60 dak. süre içerisinde $60 \mathrm{mg}$ adsorban ile muamele edildi ve 65 ${ }^{\circ} \mathrm{C}$ 'de yaklaşık \% 100 boyar madde giderme değerleri elde edildi. Ayrıca, BR46 boyar maddesi BB41 boyar maddesine göre daha yüksek bir yüzde ile giderildi. BR46 boyar maddesinin molekül ağırlığının BB41 boyar maddesine göre daha küçük olması nedeniyle adsorbanın yüzeyinde daha yüksek konsatrasyonda tutulmasina ve dolayisıyla daha yüksek verimle giderilmesinde etkili olduğu düşünülmektedir (Çizelge 2). BB41 boyar maddesi pH:7.0'de en yüksek oranda giderildi. BR46 boyar maddesi ise tüm $\mathrm{pH}$ aralıklarında \% 98 giderildi. Adsorbanın çalışılan tüm $\mathrm{pH}$ aralıklarında pozitif yüklü bazik boyalar etkileşebilecek özellikte iyon değiştirici bir membran olması nedeniyle yüksek yüzde ile boyar maddeleri giderebildiği düşünülmektedir (Şekil 4).




Şekil 4. Bazik boyar maddelerin $45^{\circ} \mathrm{C}$ ve 60 . dakikada farklı $\mathrm{pH}$ 'larda elde edilen yüzde boyar madde giderme

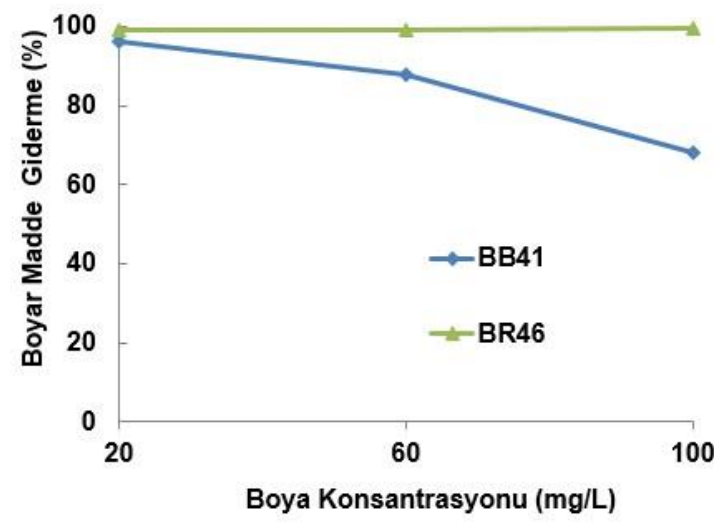

Şekil 5. pH:7,0, $45^{\circ} \mathrm{C}$ ve 60 dakika boyunca farklı başlangıç boya konsantrasyonlarında elde edilen yüzde boya giderme değerleri

Şekil 5'da BB41 boyar maddesi için artan başlangıç konsantrasyonu miktarı ile boyar madde giderimi yüzdesinde düşme gözlenirken BR 46 boyar maddesinin gideriminde başlangıç boya konsantrasyonun artması boyar maddenin giderilmesini olumsuz etkilenmedi. Şekil 6'da görüldüğü gibi adsorbanın boyar madde ile muamele süresi arttıkça boyar madde giderme yüzdesi arttı. 80. dakikada maksimuma ulaşıp daha sonra boyar madde giderme değerleri sabit kaldı. Çalışmada kullanılan boyar maddelerin Çizelge 2'de gösterilen molekül ağırlıkları dikkate alındığında molekül ağırlığı küçüldükçe boya giderme yüzdesinin arttığ dikkat çekmektedir.



Şekil 6. pH:7,0, $45^{\circ} \mathrm{C}$ ve $60 \mathrm{mg} / \mathrm{L}$ başlangıç boya konsantrasyonlarında farklı bekleme sürelerinde elde edilen $\%$ boyar madde giderme

Çizelge 3'de çeşitli bazik boyar maddelerin giderilmesinde kullanılan yöntemler ve bu çalışmalardan elde edilen sonuçlar özetlenmiştir.

Tablo 3. Bazik boyar maddelerin giderilmesinde kullanılan çeşitli yöntemler ve elde edilen yüzde boyar madde giderme değerleri

\begin{tabular}{|c|c|c|c|}
\hline Boyar madde & Yöntem/Malzeme & $\begin{array}{c}\text { \% Giderim ve Ortam koşulları (süre, sıcaklık, } \\
\text { pH) }\end{array}$ & Ref. \\
\hline Basic Blue 41 & $\begin{array}{l}\text { Adsorpsiyon/ } \\
\text { Nikel Demir Nanopartiküller }\end{array}$ & $\begin{array}{l}\text { \% 85(pH:4 ve } \mathrm{pH}: 8 \text {, süre: } 60 \text { dak., başlangıç boyar } \\
\text { madde konsantrasyonu: } 50 \mathrm{mg} / \mathrm{L} \text {, sıcaklık: } 25^{\circ} \mathrm{C} \text {, } \\
\text { karıştırma hızı: } 200 \mathrm{rpm} \text {, adsorban miktarı: } 0,3 \mathrm{~g} .)\end{array}$ & [21] \\
\hline Basic Blue 41 & $\begin{array}{l}\text { Adsorpsiyon/Magnetik } \\
\text { demir nanopartikül-alginat }\end{array}$ & $\begin{array}{l}\text { \% } 60 \text { (adsorban miktar1: } 0,3 \mathrm{~g} ; \text { süre: } 150 \text { dak., } \\
\text { maksimum adsorpsiyon pH's1: } 8,0 \text { ) }\end{array}$ & [22] \\
\hline Basic Blue 41 & Enzimatik /Kloroperoksidaz & $\begin{array}{l}\% 40 \text { (enzim) } \\
\% 15 \text { (immobilize enzim, } \mathrm{pH}: 3,25^{\circ} \mathrm{C} \text { ) }\end{array}$ & [23] \\
\hline Basic Red 46 & Elektrokoagülasyon & $\begin{array}{l}\text { \% } 95 \text { (optimum pH: } 8 \text {, başlangıç boyar madde } \\
\text { konsantrasyonu: } 50 \mathrm{mg} / \mathrm{L} \text {, süre: } 5 \text { dak.) }\end{array}$ & [24] \\
\hline Basic Red 46 & $\begin{array}{l}\text { Fotokatalitik/ immobilize } \\
\mathrm{TiO}_{2} \text { nanopartiküller }\end{array}$ & $\begin{array}{l}\% 75 \text { (pH: } 11,1, \text { başlangıç boyar madde } \\
\text { konsantrasyonu: } 17,5 \mathrm{mg} / \mathrm{L} \text {, süre: } 50 \text { dak.) }\end{array}$ & [25] \\
\hline $\begin{array}{l}\text { Basic Red } 46 \\
\text { Basic Blue } 41\end{array}$ & $\begin{array}{l}\text { Adsorpsiyon/ boron ile } \\
\text { zenginleştirilmiş atıklar }\end{array}$ & $\begin{array}{l}\text { maksimum pH: } 9,0-12,0 \\
\text { optimum } \mathrm{pH}: 9,0\end{array}$ & [17] \\
\hline $\begin{array}{l}\text { Basic Blue } 41 \\
\text { Basic Red } 18\end{array}$ & $\begin{array}{l}\text { Adsorpsiyon/ } \\
\text { modifiye kitosan }\end{array}$ & $\begin{array}{l}\left.\% 87 \text { (pH:11, süre:75 dak., sicaklık: } 40^{\circ} \mathrm{C}\right) \\
\left.\% 65 \text { (pH:11, süre: } 75 \text { dak., sicaklık: } 40^{\circ} \mathrm{C}\right)\end{array}$ & [13] \\
\hline \multirow[t]{2}{*}{ Basic Blue 41} & $\begin{array}{l}\text { Mikroorganizma/Trametes } \\
\text { versicolor } \\
\text { Adsorpsiyon/sülfonlanmış } \\
\text { polimer }\end{array}$ & \% 90 (süre: 7 gün, pH:3,6 sıcaklık: $30^{\circ} \mathrm{C}$ ) & [8] \\
\hline & $\begin{array}{l}\text { Enzimatik/Horseradish } \\
\text { Peroksidaz }\end{array}$ & $\% 30$ (150 dak., pH: 7, $\left.30^{\circ} \mathrm{C}\right)$ & \\
\hline $\begin{array}{l}\text { Basic Blue } 41 \\
\text { Basic Red } 46\end{array}$ & $\begin{array}{l}\text { Adsorpsiyon/ } \\
\text { Nafion }{ }^{\circledR} \text { membran }\end{array}$ & $\begin{array}{l}\text { \% } 100 \text { (süre: } 60 \text { dak, karıștırma hızı: } 250 \mathrm{rpm} \text {, } \\
\text { pH:7,0 sıcaklık: } 45{ }^{\circ} \mathrm{C} \text {, başlangıç boyar madde } \\
\text { konsantrasyonu: } 60 \mathrm{mg} / \mathrm{L} \text { ) }\end{array}$ & $\begin{array}{c}\text { Bu } \\
\text { çalışma }\end{array}$ \\
\hline
\end{tabular}


R. OZDOGAN/APJES 6-1 (2018) 17-24

Çizelge 3'te gösterilen literatürdeki BB41 ve BR46 boyar maddelerinin giderme yüzdeleri \% 15 ile \% 95 arasında değiştiği görülmektedir. Bu çalışmada ise $\% 100$ boyar madde giderme değerleri elde edildi. $\mathrm{Bu}$ adsorbanın maliyetli olmasına karşın onlar kez

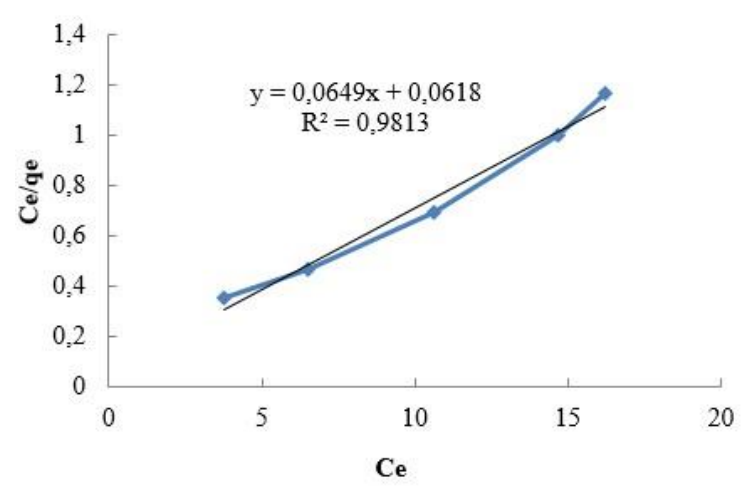

Şekil 7. Basic Blue 41 boyar maddesinin Langmuir İzotermi

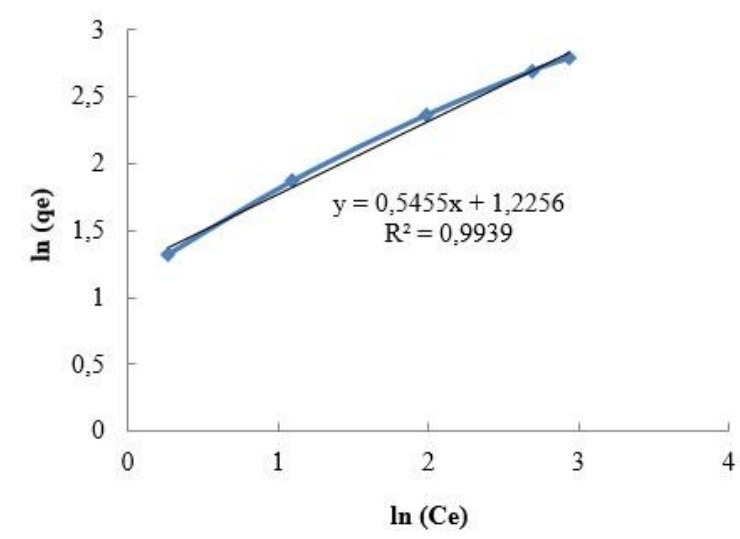

Şekil 8. Basic Blue 41 boyar maddesinin Freundlich İzotermi

Doğrunun eğiminden BB41 boyar maddesi için adsorbanın maksimum adsorplama kapasitesi, $\mathrm{q}_{\mathrm{m}}$ : 15,63 mg/L olarak bulundu. Basic Blue 41 boyar maddesi için Freundlich izoterminde elde edilen denklem kullanılarak doğrunun eğiminden $\mathrm{n}: 1.83$ ve Kf: 3,03 olarak bulundu rejenere olabilmesi ve $\% 100$ boyar madde giderme verimi nedeni ile bazik boyar maddelerin giderilmesinde alternatif olabileceği düşünülmektedir.

\section{Adsorpsiyon Kinetikleri}

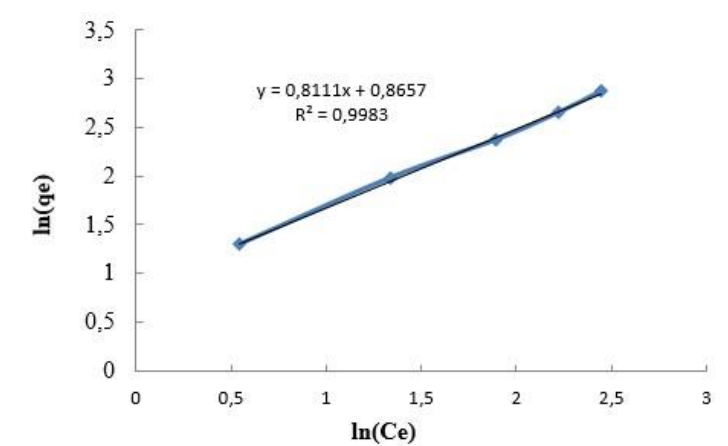

Şekil 10. Basic Red 46 boyar maddesinin Freundlich İzotermi

Şekil 9'da elde edilen Langmuir izotermi doğrusunun eğiminden BB41 boyar maddesi için adsorbanın maksimum adsorplama kapasitesi 52,63 $\mathrm{mg} / \mathrm{g}$ olarak hesapland1. Basic Red 46 boyar maddesi için doğrunun Şekil 10'da elde edilen Freundlich izotermi eğiminden $\mathrm{n}$ : 1,233 ve $\mathrm{Kf}$ ise 2,375 olarak bulundu. Nafion ${ }^{\circledR}$ membranı ile BB41 boyar madde adsorpsiyonuna ait termodinamik çalışmaları sonucunda elde edilen deneysel veriler kullanılarak hesaplanan Gibbs serbest enerjisi $(\Delta \mathrm{G})$ değerleri BB41 ve BR46 boyar maddeleri için $318 \mathrm{~K}$ sıcaklıkta sırası ile $-5.2 \mathrm{kj} / \mathrm{mol}$ ve $-5,52 \mathrm{kj} / \mathrm{mol}$ olarak bulundu. Bu sonuçlar her iki boyar maddenin de Nafion $^{\circledR}$ membranına adsorpsiyonunun kendiliğinden meydana geldiğini göstermektedir. İzotermler incelendiğinde her iki boyar maddenin polimer membranına adsorpsiyonunun Freundlich izotermine uyduğu tespit edildi.

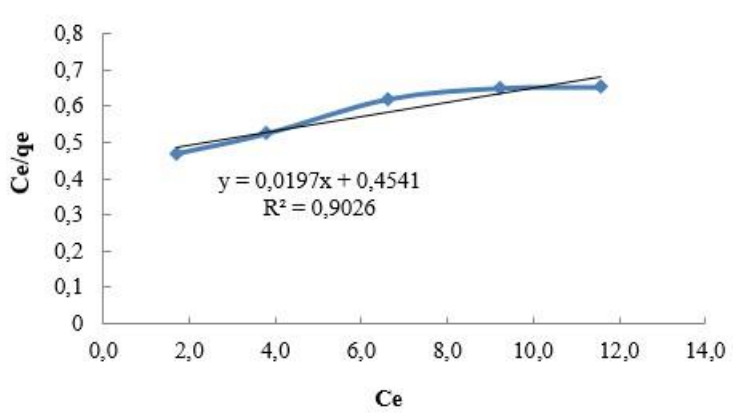

Şekil 9. Basic Red 46 boyar maddesinin Langmuir izotermi 
R. OZDOGAN/APJES 6-1 (2018) 17-24

Tablo 4. BB41 ve BR46 boyar maddeleri için adsorpsiyon kinetiklerinin literatürdeki sonuçlar ile bu çalışmadan elde edilen sonuçların karşılaştırılması

\begin{tabular}{|c|c|c|c|c|c|c|c|c|c|c|}
\hline \multirow[b]{2}{*}{ Adsorban } & \multicolumn{2}{|c|}{$\begin{array}{l}\text { Langmuir } \\
\text { Parametreleri }\end{array}$} & \multirow{2}{*}{$\begin{array}{c}\text { İzoterm } \\
\mathrm{r}^{2}\end{array}$} & \multicolumn{2}{|c|}{$\begin{array}{l}\text { Freundlich } \\
\text { Parametreleri }\end{array}$} & \multirow{2}{*}{$\begin{array}{l}\text { İzoterm } \\
\mathrm{r}^{2}\end{array}$} & \multicolumn{2}{|c|}{ Deney Koşulları } & \multirow[b]{2}{*}{$\begin{array}{l}\text { Süre, } \\
\text { sicaklık }\end{array}$} & \multirow[t]{2}{*}{ Ref. } \\
\hline & $\begin{array}{l}\mathrm{K}_{\mathrm{L}} \\
(\mathrm{L} / \mathrm{mg})\end{array}$ & $\begin{array}{l}\mathrm{q}_{\max } \\
(\mathrm{mg} / \mathrm{g})\end{array}$ & & $\mathrm{K}_{\mathrm{f}}$ & $1 / \mathrm{n}$ & & $\begin{array}{l}\text { Adsorb } \\
\text { an } \\
(\mathrm{g} / \mathrm{L})\end{array}$ & $\begin{array}{l}\text { Boyar } \\
\text { madde } \\
(\mathrm{mg} / \mathrm{L})\end{array}$ & & \\
\hline $\begin{array}{l}\text { Titanyum } \\
\text { mikroküreler } \\
\text { / BB41 }\end{array}$ & 0,776 & 142,86 & 0,966 & $\begin{array}{l}59,85 \\
7\end{array}$ & 0,237 & 0,814 & 0,6 & 60 & $\begin{array}{ll}90 & \text { dak. } \\
\text { pH: } & 9.0, \\
25^{\circ} \mathrm{C} & \end{array}$ & [26] \\
\hline $\begin{array}{l}\text { Nafion }^{\circledR} \\
\text { BB41 }\end{array}$ & 1,047 & 15,65 & 0.981 & 3.035 & 0.511 & 0.993 & 5 & 60 & $\begin{array}{l}60 \text { dak. pH: } \\
7.0,45^{\circ} \mathrm{C}\end{array}$ & $\begin{array}{l}\text { Bu } \\
\text { calıșma }\end{array}$ \\
\hline $\begin{array}{l}\text { Nafion }^{\circledR} \\
\text { BR46 }\end{array}$ & 0,042 & 52,63 & 0,902 & 2,375 & 0,811 & 0,998 & 5 & 60 & $\begin{array}{l}60 \text { dak. pH: } \\
7.0,45^{\circ} \mathrm{C}\end{array}$ & $\begin{array}{l}\text { Bu } \\
\text { çalışma }\end{array}$ \\
\hline $\begin{array}{l}\text { Moroccan } \\
\text { Clay for } \\
\text { BR46 }\end{array}$ & 1.248 & 54 & 0.99 & 31.22 & 0.23 & 0.89 & 0,4 & 10 & $\begin{array}{l}20 \text { dak. pH: } \\
6,0,30 \text { dak. } \\
25^{\circ} \mathrm{C}\end{array}$ & [27] \\
\hline $\begin{array}{lr}\text { Raw } & \text { fish } \\
\text { bone } & \text { for } \\
\text { BB41 } & \end{array}$ & - & 37.36 & - & - & - & - & 2.5 & 100 & 30 dak. & {$[28]$} \\
\hline $\begin{array}{l}\text { Boron waste } \\
\text { for BR46 }\end{array}$ & - & 38 & 0.838 & - & 0.992 & 0.862 & 2.0 & 60 & $35^{\circ} \mathrm{C} \mathrm{pH}: 9.0$ & {$[18]$} \\
\hline
\end{tabular}

$\mathrm{Bu}$ çalışmada, adsorbsiyon izotermlerinden elde edilen sonuçlarda Basic Blue 41 ve Basic Red 46 boyar maddeleri için sırası ile adsorbanın maksimum adsorplama kapasitesi $15,65 \mathrm{mg} / \mathrm{g}$ ve $52,63 \mathrm{mg} / \mathrm{g}$ olarak bulunmuştur (Çizelge 4). Boya giderme yüzdesinde de olduğu gibi adsorpsiyon kinetik çalışmaları sonucunda adsorpsiyon izotermlerinden elde edilen sonuçlar Basic Red 46 boyar maddesinin Basic Blue 41 boyar maddesine göre daha yüksek bir konsantrasyonda adsorplandığı ortaya çıkmıştır. BR46 boyar maddesinin molekül ağırlığı BB41 boyar maddesinden daha küçük olduğu için adsorban yüzeyinde daha yüksek konsantrasyonda adsorplandığı düşnülmektedir.

\section{DEĞERLENDİRME VE SONUÇ}

Bu çalışmada, akrilik elyaf boyanmasında kullanılan bazik boyar maddelerin kumaşa boyanma sonras1 tutunmadan kalan boyar maddelerden oluşan rengin giderilerek çevreye zararsız hale getirilmesi amaçlandı. Bu amaca ulaşmak için perfluorosülfonik asit esasli polimerik membran $\left(\right.$ Nafion $\left.^{\circledR}\right)$ kullanıld1. Bazik boyar maddeye gore farklı boya giderme yüzdeleri elde edildi. Boyar maddenin molekül büyüklüğünün küçülmesi adsorban polimerik membranın daha küçük gözeneklerine girmesine ve tutunmasına yol açtığ BR46 boyar maddesi diğer boyar maddelere göre daha yüksek boya giderme yüzdesi ile giderildi. Sıcaklığın artması boyar maddelerin boya giderme yüzdelerini belirgin bir şekilde arttırdı. Bu çalışmada kullanılan polimerik membranın maliyeti yüksektir. Rejenere olabilen daha ucuz maliyetle üretilebilecek polimerlerik adsorbanların üretilmesi bazik boyar maddelerin daha ekonomik bir şekilde atık sulardan giderilmesine fayda sağlayacaktır.

Adsorban maliyetli olmasına karşı en az $20 \mathrm{kez}$ rejenere olarak tekrar kullanılabilen bir adsorbandır. Ayrıca literatürde de bazik boyaların giderilmesinde kullanılmadığından, termal, mekanik dayanımı yüksek, esnek ve onlarca kez rejenere olabilen bir adsorban olduğu için bu çalışmada tercih edildi.

\section{TEŞEKKÜR}

$\mathrm{Bu}$ çalışma Yalova Üniversitesi (Proje No: 2014/BAP/083) tarafindan desteklenmiştir.

\section{KAYNAKÇA}

[1] P. M. Roosta M, Ghaedi M, Daneshfar A, Darafarin S, Sahraei R, "Simultaneous ultrasoundassisted removal of sunset yellow and erythrosine by $\mathrm{ZnS}$ :Ni nanoparticles loaded on activated carbon: Optimization by central composite design," Desalin. Water Treat., vol. 52, no. 2, pp. 193-202, 2014.

[2] S. Song, J. Yao, Z. He, J. Qiu, and J. Chen, "Effect of operational parameters on the decolorization of C.I. Reactive Blue 19 in aqueous solution by ozone-enhanced electrocoagulation," $J$. Hazard. Mater., vol. 152, no. 1, pp. 204-210, 2008. [3] M. Celebi, Tekstil Atık Sularında Boyaların Biyobozunma ile Giderilmesi. 2013.

[4] Baser İnci Inanıc Yusuf, Boyar Madde Kimyast. Teknik Eğitim Fakültesi Marmara Üniversitesi, 1990.

[5] Q. Husain, "Potential Applications of the Oxidoreductive Enzymes in the Decolorization and Detoxification of Textile and Other Synthetic Dyes 
from Polluted Water: A Review," Crit. Rev. Biotechnol., vol. 26, no. 4, pp. 201-221, 2006.

[6] M. Çelebi, Tekstil Atık Sularında Boyaların Biyobozunma ile Giderilmesi, Kısaltılmış Doktora Tezi. İstanbul Sanayi Odası Yayınları, 2013.

[7] M. Celebi, M. Altikatoglu, Z. M. Akdeste, and H. Yildirim, "Determination of decolorization properties of Reactive Blue 19 dye using Horseradish Peroxidase enzyme," Horseradish Peroksidaz enzimi Kullan. React. Blue 19 boyasi\{dotless\}ni\{dotless\}n renk giderilmesinin belirlenmesi, vol. 38, pp. 200-206, 2013.

[8] M. Celebi, M. Arif, M. Altikatoglu, and H. Yildirim, "Removal of Cationic Dye from Textile Industry Wastewater with Using Enzyme, Fungus and Polymer," vol. 3, no. 2, pp. 39-45, 2013.

[9] S. H. Lin and C. S. Wang, "Treatment of highstrength phenolic wastewater by a new two-step method," J. Hazard. Mater., vol. 90, no. 2, pp. 205216, 2002.

[10] M. Al-Aseeri, Q. Bu-Ali, S. Haji, and N. AlBastaki, "Removal of Acid Red and sodium chloride mixtures from aqueous solutions using nanofiltration," Desalination, vol. 206, no. 1-3, pp. 407-413, 2007.

[11] F. Harrelkas, A. Paulo, M. M. Alves, L. El Khadir, O. Zahraa, M. N. Pons, and F. P. van der Zee, "Photocatalytic and combined anaerobicphotocatalytic treatment of textile dyes," Chemosphere, vol. 72, no. 11, pp. 1816-1822, 2008. [12] C. A. Basha, K. V. Selvakumar, H. J. Prabhu, P. Sivashanmugam, and C. W. Lee, "Degradation studies for textile reactive dye by combined electrochemical, microbial and photocatalytic methods," Sep. Purif. Technol., vol. 79, no. 3, pp. 303-309, 2011.

[13] M. Sadeghi-Kiakhani, M. Arami, and K. Gharanjig, "Preparation of chitosan-ethyl acrylate as a biopolymer adsorbent for basic dyes removal from colored solutions," J. Environ. Chem. Eng., vol. 1, no. 3, pp. 406-415, 2013.

[14] T. S. Anirudhan and M. Ramachandran, "Adsorptive removal of basic dyes from aqueous solutions by surfactant modified bentonite clay (organoclay): Kinetic and competitive adsorption isotherm," Process Saf. Environ. Prot., vol. 95, pp. 215-225, 2015.

[15] B. H. Hameed and M. I. El-Khaiary, "Removal of basic dye from aqueous medium using a novel agricultural waste material: Pumpkin seed hull," $J$. Hazard. Mater., vol. 155, no. 3, pp. 601-609, 2008. [16] B. H. Hameed, R. R. Krishni, and S. A. Sata, "A novel agricultural waste adsorbent for the removal of cationic dye from aqueous solutions," J. Hazard. Mater., vol. 162, no. 1, pp. 305-311, 2009.

[17] V. K. Gupta, S. Agarwal, A. Olgun, H. I. Demir,
M. L. Yola, and N. Atar, "Adsorptive properties of molasses modified boron enrichment waste based nanoclay for removal of basic dyes," J. Ind. Eng. Chem., vol. 34, pp. 244-249, 2016.

[18] A. Olgun and N. Atar, "Equilibrium and kinetic adsorption study of Basic Yellow 28 and Basic Red 46 by a boron industry waste," J. Hazard. Mater., vol. 161, no. 1, pp. 148-156, 2009.

[19] G. Z. Kyzas and N. K. Lazaridis, "Reactive and basic dyes removal by sorption onto chitosan derivatives," J. Colloid Interface Sci., vol. 331, no. 1, pp. 32-39, 2009.

[20] Y. Zhou, L. Zhang, and Z. Cheng, "Removal of organic pollutants from aqueous solution using agricultural wastes: A review," Journal of Molecular Liquids, vol. 212. pp. 739-762, 2015.

[21] N. M. Mahmoodi, "Nickel ferrite nanoparticle: Synthesis, modification by surfactant and dye removal ability," Water. Air. Soil Pollut., vol. 224, no. 2, 2013.

[22] N. M. Mahmoodi, "Magnetic ferrite nanoparticle-alginate composite: Synthesis, characterization and binary system dye removal," $J$. Taiwan Inst. Chem. Eng., vol. 44, no. 2, pp. 322330, 2013.

[23] E. Guerrero, P. Aburto, E. Terrés, O. Villegas, E. González, T. Zayas, F. Hernández, and E. Torres, "Improvement of catalytic efficiency of chloroperoxidase by its covalent immobilization on SBA-15 for azo dye oxidation," J. Porous Mater., vol. 20, no. 2, pp. 387-396, 2013.

[24] N. Daneshvar, A. Oladegaragoze, and N. Djafarzadeh, "Decolorization of basic dye solutions by electrocoagulation: An investigation of the effect of operational parameters," J. Hazard. Mater., vol. 129, no. 1-3, pp. 116-122, 2006.

[25] A. R. Khataee, "Photocatalytic removal of CI Basic Red 46 on immobilized TiO2 nanoparticles: Artificial neural network modelling," Environ. Technol., vol. 30, no. 11, pp. 1155-1168, 2009.

[26] Y. Jiang, Y. Luo, F. Zhang, L. Guo, and L. Ni, "Equilibrium and kinetic studies of C.I. Basic Blue 41 adsorption onto N, F-codoped flower-like TiO2 microspheres," Appl. Surf. Sci., vol. 273, pp. 448456, 2013.

[27] A. B. Karim, B. Mounir, M. Hachkar, M. Bakasse, and A. Yaacoubi, "Removal of Basic Red 46 dye from aqueous solution by adsorption onto Moroccan clay," J. Hazard. Mater., vol. 168, no. 1, pp. 304-309, 2009.

[28] A. Ebrahimi, M. Arami, H. Bahrami, and E. Pajootan, "Fish Bone as a Low-Cost Adsorbent for Dye Removal from Wastewater: Response Surface Methodology and Classical Method," Environ. Model. Assess., vol. 18, no. 6, pp. 661-670, 2013. 